\title{
Poststroke Cognitive Decline: A Longitudinal Study from a Tertiary Care Center
}

\author{
Rameshwar Nath Chaurasia ${ }^{1} \quad$ jitendra Sharma ${ }^{1} \quad$ Abhishek Pathak $^{1}$ Vijay Nath Mishra ${ }^{1} \quad$ Deepika Joshi $^{1}$ \\ ${ }^{1}$ Department of Neurology, Institute of Medical Science, Banaras \\ Address for correspondence Rameshwar Nath Chaurasia, DM, \\ Department of Neurology, Institute of Medical Science, Banaras \\ Hindu University, Varanasi, 221 005, Uttar Pradesh, India \\ (e-mail: goforrameshwar@gmail.com).
}

J Neurosci Rural Pract 2019;00:459-464

\begin{abstract}
Keywords

- Mini-Mental State

Examination

- Montreal Cognitive Assessment

- poststroke cognitive decline

- prevalence
\end{abstract}

Objectives Poststroke cognitive decline (PSCD) is a serious disabling consequence of stroke. The purpose of this study is to find the prevalence of PSCD and sociodemographic and clinical determinants of risk factors of PSCD.

Materials and Methods This study was a prospective, hospital-based study conducted on 200 stroke patients from stroke registry during October 2015 to April 2017. Detailed clinical evaluation was done. Mini-Mental State Examination (MMSE) and Montreal Cognitive Assessment (MoCA) scores were used to determine PSCD after 3 and 6 months as per the Diagnostic and Statistical Manual of Mental Disorders V. Chisquared test was used to find the association between two variables. The Wilcoxon signed-rank test was used to compare the difference in cognitive impairment between two follow-ups at 3 and 6 months, respectively. A p-value $<0.05$ was considered statistically significant.

Results The prevalence of PSCD measured by MoCA scale at 3 and 6 months was 67 and $31.6 \%$, respectively. By MMSE scale, cognitive decline prevalence at 3 months was found to be $87(46.3 \%)$, which reduced to $22(17.1 \%)$ at 6 months. The association between MMSE scale and type of stroke was significant at 3 months.

Conclusion One-third of the stroke patients developed PSCD within 3 months of onset of stroke, with different levels of severity. The major predictors of new-onset poststroke cognitive impairment were diabetes and hypertension. The prevalence of PSCD reduced significantly at 6 months of stroke on follow-up.

\section{Introduction}

Stroke or cerebrovascular accident is the dysfunction of brain due to a disturbance in the cerebral blood flow. It is a global health problem and a major cause of disability. ${ }^{1}$ Cognitive decline is an important but less studied consequence of stroke. It can be either due to aging or due to stroke. Cognitive decline associated with normal aging does not lead to impairment in daily routine activities. However, decline in cognition due to stroke may cause mild-to-severe impairment of the same. A recent study among elderly people living in slum-urban areas of Asia's largest slum at Dharavi, Mumbai, showed confirmed stroke prevalence to be $44 \%$, and among these, poststroke cognitive decline (PSCD) was found to be $66.6 \%{ }^{2}$ According to Nys et al, a large number of stroke survivors developed cognitive impairment within 3 months after stroke. ${ }^{3}$ Another study by Sundar and Adwani used Mini-Mental State Examination (MMSE) score to measure cognitive decline and found its prevalence to be $31.7 \%$ among 164 patients. ${ }^{4}$ The few other prospective studies in India showed that the prevalence of cognitive impairment was $\sim 20 \%$ among total stroke survivors. ${ }^{5}$ In a recent study in India of 50 stroke patients, it was observed that $72 \%$ patients have some form of cognitive decline. ${ }^{6}$

There is a lack of research on cognitive decline in Indian context. Since India is a developing country with a rapid 
increase in older population every year, there would be a large number of stroke survivors with cognitive decline. Therefore, it is very important to study about the prevalence and risk factors of PSCD.

\section{Materials and Methods}

This study was a prospective tertiary hospital-based study conducted from October 2015 to April 2017 in the Department of Neurology, Institute of Medical Sciences, Banaras Hindu University, Varanasi, India. A total of 200 consecutive patients were included in the study from stroke registry. A valid informed consent was obtained from each patient. All the patients were subjected to a detailed clinical history and physi$\mathrm{cal}$, neurological, and radiological examination as per the standard protocol prepared by us. The history of any illness, history of chronic illness, personal history of addiction, occupational history, dietary habits, and family history were taken in detail.

\section{Stroke Registration}

By definition, stroke is considered as rapidly developing clinical signs of local or global loss of cerebral function that last for more than 24 hours or lead to death within 24 hours. The International Classification of Diseases (ICD), 10th Revision, was used to classify the types of stroke. Events were classified as cerebral infarction (ischemic; ICD 163), intracerebral hemorrhage (ICD 161), and subarachnoid hemorrhage (ICD 160). Subtypes of ischemic stroke were coded according to the TOAST classification. Patients with transient ischemic attacks were excluded. The subtype of stroke was verified by computed tomography and MRI of brain.

\section{Inclusion Criteria}

1. All patients with first-ever acute stroke ( $<1$ week) admitted in the neurology ward of Sir Sunderlal Hospital from October 2015 to April 2017 were included.

2. The Folstein MMSE and Montreal Cognitive Assessment (MoCA) scores were used to determine cognitive decline after 3 and 6 months as per the Diagnostic and Statistical Manual of Mental Disorders V. MMSE grade score was categorized as per the standardized protocol, which if comes to $\geq 24-$ normal, 20-23-mild cognitive decline, $10-19$ - moderate cognitive decline, and $\leq 9-$ severe. MoCA score $<26$ indicates cognitive decline.

3. The World Health Organization guidelines were used to measure all blood parameters.

4. Hypertension was classified as per the Joint National Committee 8.

\section{Exclusion Criteria}

1. Patients unconscious at the time of admission and uncooperative, blind, and deaf patients.

2. Patients having transient ischemic attacks and cerebral venous thrombosis.

3. Pediatric age group patients were excluded (up to 14 years).

\section{Statistical Analysis}

SPSS 16.0, IBM corporation, was used for analysis purpose. Kuppuswamy's socioeconomic scale was used to measure socioeconomic status. Univariate and bivariate analyses (number and percentage) were done for basic sociodemographic characteristics. Chi-squared test was used to see the association between two variables. The Wilcoxon signed-rank test was used to check the difference in cognitive impairment between two follow-ups at 3 and 6 months, respectively. Statistical significance was recognized when $p<0.05$.

\section{Results}

Among the 200 patients, 12 patients died before the first follow-up at 3 months while 1 patient died between the first and second follow-up, which was done at 6 months. Basic sociodemographic and clinical characteristics of stroke patients were shown in - Table 1. The majority (127; 65.5\%) of the patients are older than 60 years, followed by 64 (32.0\%) between 41 and 60 years and only 9 (4.5\%) below 40 years. The mean age of patients is 64 years with a standard deviation of 12 years. Furthermore, sex-wise distribution of stroke patients shows that three-fourths of the patients, that is, 147 (73.5\%), were male and 53 (26.5\%) patients were female. The majority $(141 ; 70.5 \%)$ of the patients had education up to primary level and 41 (20.5\%) had more than primary education, while $18(9.0 \%)$ patients were illiterate. In our study, the economic status of the patients was measured according to Kuppuswamy's socioeconomic scale. According to this scale, 48 (24.0\%) patients belonged to lower class, 130 (65.0\%) belonged to middle class, and $22(11.0 \%)$ belonged to upper class. The majority of the strokes were ischemic 113 (56.5\%), whereas 87 (43.5\%) were hemorrhagic. According to the TOAST classification of Ischemic stroke, the majority of the patients had small vessel disease $65(57.5 \%)$, large vessel disease 28 (24.7), and cardioembolic 20 (17.8\%).

Poststroke cognitive disability was measured by MoCA and MMSE scales, and respective scores have been presented in - Table 2. In this study, PSCD was seen in 126 (67\%) of the cases at 3 months by MoCA scale. Later on, PSCD prevalence by MoCA scale at the second follow-up at 6 months reduced to 59 (31.6\%). Of 80 cases in hemorrhagic group, 50 (62.5\%) had cognitive decline at 3 months and it reduced to $20(25.0 \%)$ at 6-month follow-up. Of 108 cases in ischemic group, 76 (70.4\%) had cognitive decline at 3 months, which reduced to $39(36.4 \%)$ at 6 -month follow-up. The association between MoCA scale and type of stroke was not significant at 3 and 6 months.

By MMSE scale, cognitive decline prevalence at 3 months was found to be $87(46.3 \%$, ) which reduced to $22(17.1 \%)$ at 6 months. At 3 months, 32 (17.0\%) had mild cognitive decline, $44(23.4 \%)$ had moderate, and $11(5.9 \%)$ had severe cognitive decline. Of 80 cases in hemorrhagic group, 18 (22.5\%) had mild cognitive decline at 3 months, which reduced to $8(10.0 \%)$ at 6 months. Of 108 cases in the ischemic group, $14(13.0 \%)$ had mild cognitive decline at 3 months, which increased to $17(15.9 \%)$ at 6 months. Further 35 (32.4\%) had moderate cognitive decline, which reduced to $6(5.6 \%)$ 
Table 1 Sociodemographic and clinical characteristics of stroke patients under study $(n=200)$

\begin{tabular}{|c|c|}
\hline Basic characteristics & Stroke patients, frequency (\%) \\
\hline \multicolumn{2}{|l|}{ Age, y } \\
\hline Young (up to 40) & $9(4.5)$ \\
\hline Middle (41-60) & $64(32.0)$ \\
\hline Old (above 60) & $127(65.5)$ \\
\hline Mean \pm SD & $64.17 \pm 12.23$ \\
\hline \multicolumn{2}{|l|}{ Sex } \\
\hline Male & $147(73.5)$ \\
\hline Female & $53(26.5)$ \\
\hline \multicolumn{2}{|l|}{ Education } \\
\hline Illiterate & $18(9.0)$ \\
\hline Primary & $141(70.5)$ \\
\hline Above & $41(20.5)$ \\
\hline \multicolumn{2}{|l|}{ Socioeconomic status } \\
\hline Lower & $48(24.0)$ \\
\hline Middle & $130(65.0)$ \\
\hline Upper & $22(11.0)$ \\
\hline \multicolumn{2}{|l|}{ Occupation } \\
\hline Business & $21(10.5)$ \\
\hline Farmer & $63(31.5)$ \\
\hline Housewife & $50(25.0)$ \\
\hline Retired & $59(29.5)$ \\
\hline Other & $7(3.5)$ \\
\hline \multicolumn{2}{|l|}{ Family history of stroke } \\
\hline Yes & $5(2.5)$ \\
\hline No & 195 (97.5) \\
\hline \multicolumn{2}{|l|}{ Type of stroke } \\
\hline Hemorrhagic & $87(43.5)$ \\
\hline Ischemic & $113(56.5)$ \\
\hline \multicolumn{2}{|l|}{ Hypertension } \\
\hline Yes & $69(34.5)$ \\
\hline No & $131(65.5)$ \\
\hline \multicolumn{2}{|l|}{ Diabetes } \\
\hline Yes & $77(38.5)$ \\
\hline No & $123(61.5)$ \\
\hline
\end{tabular}

Abbreviation: SD, standard deviation.

at 6 months. At 3-month follow-up, 11 (10.2\%) patients had severe cognitive decline but at 6-month follow-up, there were no cases of cognitive decline (- Table 3 ).

The association between cognitive decline measured by MoCA scale at 3 months with different predictors such as age, sex, education, occupation, socioeconomic status, type of stroke, hypertension, and diabetes is shown in - Table 4. We used chi-squared test to see the association between cognitive decline and its predictors, and we found hypertension
Table 2 Poststroke cognitive disability scores

\begin{tabular}{|l|l|}
\hline Disability scores & $\boldsymbol{n}(\%)$ \\
\hline MoCA (3 mo) & 188 \\
\hline Normal & $62(33.0)$ \\
\hline Cognitive decline & $126(67.0)$ \\
\hline Mean \pm SD & $23.23 \pm 3.03$ \\
\hline MoCA (6 mo) & 187 \\
\hline Normal & $128(68.4)$ \\
\hline Cognitive decline & $59(31.6)$ \\
\hline Mean \pm SD & $25.74 \pm 2.28$ \\
\hline MMSE (3 mo) & 188 \\
\hline Normal & $101(53.7)$ \\
\hline Mild & $32(17.0)$ \\
\hline Moderate & $44(23.4)$ \\
\hline Severe & $11(5.9)$ \\
\hline Mean \pm SD & $22.62 \pm 2.94$ \\
\hline MMSE (6 mo) & 187 \\
\hline Normal & $155(82.9)$ \\
\hline Mild & $25(13.4)$ \\
\hline Moderate & $7(3.7)$ \\
\hline Severe & $0(0.0)$ \\
\hline Mean \pm SD & $24.89 \pm 2.03$ \\
\hline
\end{tabular}

Abbreviations: MMSE, Mini-Mental State Examination; MoCA, Montreal Cognitive Assessment; SD, standard deviation.

Table 3 Comparison of types of stroke with different cognitive scales

\begin{tabular}{|c|c|c|c|}
\hline \multirow[t]{2}{*}{ Scale } & \multicolumn{2}{|c|}{ Type of stroke } & \multirow[t]{2}{*}{$p$-Value } \\
\hline & Ischemic & Hemorrhagic & \\
\hline \multicolumn{4}{|l|}{ MoCA at $3 \mathrm{mo}$} \\
\hline Normal & 32 & 30 & \multirow[t]{2}{*}{0.525} \\
\hline Cognitive decline & 76 & 50 & \\
\hline \multicolumn{4}{|l|}{ MoCA at 6 mo } \\
\hline Normal & 68 & 60 & \multirow[t]{2}{*}{0.181} \\
\hline Cognitive decline & 39 & 20 & \\
\hline \multicolumn{4}{|l|}{ MMSE at $3 \mathrm{mo}$} \\
\hline Normal & 48 & 53 & \multirow[t]{4}{*}{$0.000^{\mathrm{a}}$} \\
\hline Mild & 14 & 18 & \\
\hline Moderate & 35 & 9 & \\
\hline Severe & 11 & 0 & \\
\hline \multicolumn{4}{|l|}{ MMSE at 6 mo } \\
\hline Normal & 84 & 71 & \multirow[t]{4}{*}{0.295} \\
\hline Mild & 17 & 8 & \\
\hline Moderate & 6 & 1 & \\
\hline Severe & 0 & 0 & \\
\hline
\end{tabular}

Abbreviations: MMSE, Mini-Mental State Examination; MoCA, Montreal Cognitive Assessment.

aSignificant at $95 \%$. 
Table 4 Comparison of cognitive decline measure by Montreal Cognitive Assessment at 3 months with its various predictors

\begin{tabular}{|c|c|c|c|}
\hline \multirow[t]{2}{*}{$\begin{array}{l}\text { Basic } \\
\text { characteristics }\end{array}$} & \multicolumn{2}{|c|}{$\begin{array}{l}\text { Poststroke cognitive } \\
\text { decline }\end{array}$} & \multirow[t]{2}{*}{$p$-Value } \\
\hline & No & Yes & \\
\hline \multicolumn{4}{|l|}{ Age, y } \\
\hline Young (Up to 40) & 5 & 3 & \multirow[t]{3}{*}{0.142} \\
\hline Middle (41-60) & 21 & 38 & \\
\hline Old (above 60) & 36 & 85 & \\
\hline \multicolumn{4}{|l|}{ Sex } \\
\hline Male & 45 & 92 & \multirow[t]{2}{*}{0.541} \\
\hline Female & 17 & 34 & \\
\hline \multicolumn{4}{|l|}{ Education } \\
\hline Illiterate & 6 & 12 & \multirow[t]{3}{*}{0.621} \\
\hline Primary & 47 & 86 & \\
\hline Above & 9 & 28 & \\
\hline \multicolumn{4}{|l|}{$\begin{array}{l}\text { Socioeconomic } \\
\text { status }\end{array}$} \\
\hline Lower & 11 & 34 & \multirow[t]{3}{*}{0.308} \\
\hline Middle & 43 & 78 & \\
\hline Upper & 8 & 14 & \\
\hline \multicolumn{4}{|l|}{ Occupation } \\
\hline Business & 8 & 13 & \multirow[t]{5}{*}{0.568} \\
\hline Farmer & 21 & 37 & \\
\hline Housewife & 16 & 33 & \\
\hline Retired & 14 & 41 & \\
\hline Other & 1 & 3 & \\
\hline \multicolumn{4}{|l|}{ Type of stroke } \\
\hline Hemorrhagic & 31 & 50 & \multirow[t]{2}{*}{0.525} \\
\hline Ischemic & 32 & 76 & \\
\hline \multicolumn{4}{|l|}{ Hypertension } \\
\hline Yes & 23 & 38 & \multirow[t]{2}{*}{$0.039^{a}$} \\
\hline No & 63 & 64 & \\
\hline \multicolumn{4}{|l|}{ Diabetes } \\
\hline Yes & 21 & 56 & \multirow[t]{2}{*}{$0.031^{\mathrm{a}}$} \\
\hline No & 62 & 49 & \\
\hline
\end{tabular}

aSignificant at $95 \%$.

and diabetes as significant predictors. To compare the change in cognitive decline by MMSE scale at 3 and 6 months, we used the Wilcoxon signed-rank test and found significant improvement in prevalence. Similarly, we tested for MoCA scale and found significant improvement in cognitive decline from 3 months to 6 months (-Table 5 ).

\section{Discussion}

In most of the previous studies, cognitive decline was measured by MMSE and neuropsychological test batteries. In the Netherlands, the Maastricht CODAS, which examined first-ever poststroke cognitive impairment after 6 months by MMSE, has suggested the prevalence up to $70 \% .^{7}$ The studies in Australia have shown that cognitive impairment prevalence at 3 months after stroke is 50 to $58 \%$ and were based on a series of neuropsychological tests. ${ }^{8,9}$

The various studies measured poststroke cognitive impairment at 3 months and found its prevalence between 30 and 69.3\%.10-12 In a Caribbean study on 293 stroke patients at 5 years after first-ever stroke, it showed that $58.9 \%$ patients suffered from the cognitive impairment. ${ }^{13}$ Zhou et al examined the cognitive function of 434 patients with stroke on 1-year follow-up in Chongqing and found a prevalence of $37.1 \%$ at 3 months. ${ }^{14}$ The study on 252 Singaporean patients within 6 months of poststroke showed that $44 \%$ patients suffered from the cognitive decline, while the prevalence declined to $34 \%$ in 1 -year follow-up. ${ }^{15}$

In this study, PSCD was found in $67 \%$ of the cases at 3 months, which is within the range mentioned in previous studies. In del Ser et al's study, cognitive status at 24 months was stable in most cases (151; 78.2\%), worsened in 27 (14\%; 6 demented and 21 nondemented), and improved in 15 (7.8\%; 7 demented and 8 nondemented). ${ }^{10}$ While in our study, we saw significant improvement in cognition of $35.4 \%$, that is, from $67 \%$ at 3 months to $31.6 \%$ at 6 months. The possible reasons for this improvement may be neuroplasticity during recovery phase. Another study by Mahon et al showed 84\% cognitive impairment by MoCA and cognitive functioning, which significantly declined by $2.8 \%, 4$ years after stroke. ${ }^{16}$

In our study, the prevalence of PSCD by MoCA was 67.0 and $46.3 \%$ by MMSE at 3 months, which was around 20\% higher. During follow-up at 6 months, the prevalence of cognitive decline by MoCA was 31.6 and 18.1\% by MMSE. However, the mean change in MoCA and MMSE score between 3 and 6 months was almost same (2.27 in MMSE score and 2.51 in MoCA score) and this improvement in cognition was found to be statistically significant. In previous studies also, it has been observed that MoCA scale showed early and higher prevalence of PSCD than MMSE scale. ${ }^{17,18}$ Therefore, MoCA scale is more sensitive than MMSE scale to detect the early poststroke cognitive impairment. Many past studies have shown MoCA scale to be more efficient and more valid than MMSE for PSCD measurement. ${ }^{19-21}$ On subgroup analysis in the ischemic group, we saw an increase in the number of cases with mild impairment in cognition because of shift of cases from severe and moderate cognitive decline group into mild cognitive decline and normal cognition groups. In a recent study on 212 patients in Korea, cognitive improvement was observed from cognition level at admission to cognition level at discharge. However, they have not mentioned the mean duration of stay of patients at hospital. ${ }^{22}$ They used MoCA as well as MMSE to measure cognitive decline and studied the correlation between MoCA and functional outcome among subacute stroke patients with cognitive dysfunction. On investigation, they found that the group with high MoCA scores showed better functional outcome in the subacute stroke phase. 
Table 5 Comparison of Mini-Mental State Examination scale and Montreal Cognitive Assessment scale at 3 and 6 months

\begin{tabular}{|l|l|l|l|l|l|l|}
\hline & $n$ & Mean \pm SD & Median & IQR & $\begin{array}{l}\text { Wilcoxon signed-rank } \\
\text { test }\end{array}$ & $p$-Value \\
\hline $\begin{array}{l}\text { MMSE score (after } \\
\text { 3-mo follow-up) }\end{array}$ & 188 & $22.61 \pm 2.94$ & 24.00 & 4.00 & -8.759 & 0.000 \\
\hline $\begin{array}{l}\text { MMSE score (after } \\
\text { 6-mo follow-up) }\end{array}$ & 187 & $24.89 \pm 2.03$ & 26.00 & 2.00 & Difference is significant & \\
\hline $\begin{array}{l}\text { MoCA score (after } \\
\text { 3-mo follow-up) }\end{array}$ & 188 & $23.22 \pm 3.02$ & 24.00 & 5.75 & -9.656 & 0.000 \\
\hline $\begin{array}{l}\text { MoCA score (after } \\
\text { 6-mo follow-up) }\end{array}$ & 187 & $25.74 \pm 2.30$ & 26.00 & 4.00 & Difference is significant & \\
\hline
\end{tabular}

Abbreviations: IQR, interquartile range; MMSE, Mini-Mental State Examination; MoCA, Montreal Cognitive Assessment; SD, standard deviation.

There are many risk factors for stroke/recurrent strokes and cognitive impairments such as increasing age after 65 years, lower educational level, hypertension, diabetes mellitus, dyslipidemia, smoking, and atrial fibrillation. However, their association with first-ever poststroke cognitive impairment is still debatable.

There is quite discrepancy among the past studies regarding age, sex, and education as a predictor of cognitive decline. A few studies have shown education as a significant predictor of cognitive decline, ${ }^{12,16,21-24}$ while few have shown that it is an insignificant predictor. ${ }^{25}$ In our study, we found that age, sex, education, duration, and occupation were insignificant predictors for PSCD while diabetes and hypertension were found to be significant predictors. A study done by Mahon et a ${ }^{16}$ showed that sex (male) and occupation (unemployed) were also significant predictors of PSCD. In a study by Mok et al, ${ }^{12}$ age, education, and old stroke/recurrent stroke cases were found to be significant predictors of PSCD while in Korean study, age, education, and duration from onset to admission period were found to be significant predictors of poststroke cognitive impairment. ${ }^{21}$ Both the studies by Mok and Korean group have not given any explanation why there was more cognitive impairment in uneducated and unemployed patients.

\section{Conclusion}

The prevalence of PSCD falls in the range of 20 to $80 \%$ and such a vast difference is mainly due to various factors such as difference in races, duration of study, and the diagnostic criteria applied in the studies. In this study, only hypertension and diabetes were found to be significant predictors for new-onset PSCD. Our data have shown significant improvement among patients having cognitive decline from 3 to 6 months.

\section{Funding}

None.

\section{Conflict of Interest}

None declared.

\section{References}

1 Donnan GA, Fisher M, Macleod M, Davis SM. Stroke. Lancet 2008;371(9624):1612-1623
2 Mukhopadhyay A, Sundar U, Adwani S, Pandit D. Prevalence of stroke and post-stroke cognitive impairment in the elderly in Dharavi, Mumbai. J Assoc Physicians India 2012;60:29-32

3 Nys GM, van Zandvoort MJ, de Kort PL, Jansen BP, de Haan EH, Kappelle LJ. Cognitive disorders in acute stroke: prevalence and clinical determinants. Cerebrovasc Dis 2007;23(5/6):408-416

4 Sundar U, Adwani S. Post-stroke cognitive impairment at 3 months. Ann Indian Acad Neurol 2010;13(1):42-46

5 Das S, Paul N, Hazra A, et al. Cognitive dysfunction in stroke survivors: a community-based prospective study from Kolkata, India. J Stroke Cerebrovasc Dis 2013;22(8):1233-1242

6 Renjen PN, Gauba C, Chaudhari D. Cognitive impairment after stroke. Cureus 2015;7(9):e335

7 Rasquin SM, Lodder J, Ponds RW, Winkens I, Jolles J, Verhey FR. Cognitive functioning after stroke: a one-year follow-up study. Dement Geriatr Cogn Disord 2004;18(2):138-144

8 Sachdev PS, Brodaty H, Valenzuela MJ, et al. Clinical determinants of dementia and mild cognitive impairment following ischaemic stroke: the Sydney Stroke Study. Dement Geriatr Cogn Disord 2006;21(5-6):275-283

9 Srikanth VK, Anderson JF, Donnan GA, et al. Progressive dementia after first-ever stroke: a community-based follow-up study. Neurology 2004;63(5):785-792

10 del Ser T, Barba R, Morin MM, et al. Evolution of cognitive impairment after stroke and risk factors for delayed progression. Stroke 2005;36(12):2670-2675

$11 \mathrm{Yu} \mathrm{KH}$, Cho SJ, Oh MS, et al. Korean-Vascular Cognitive Impairment Harmonization Standards Study Group. Cognitive impairment evaluated with Vascular Cognitive Impairment Harmonization Standards in a multicenter prospective stroke cohort in Korea. Stroke 2013;44(3):786-788

12 Mok VC, Wong A, Lam WW, et al. Cognitive impairment and functional outcome after stroke associated with small vessel disease. J Neurol Neurosurg Psychiatry 2004;75(4):560-566

13 Chausson N, Olindo S, Cabre P, Saint-Vil M, Smadja D. Five-year outcome of a stroke cohort in Martinique, French West Indies: Etude Réalisée en Martinique et Centrée sur l'Incidence des Accidents vasculaires cérebraux, Part 2. Stroke 2010;41(4):594-599

14 Zhou DH, Wang JY, Li J, Deng J, Gao C, Chen M. Frequency and risk factors of vascular cognitive impairment three months after ischemic stroke in China: the Chongqing stroke study. Neuroepidemiology 2005;24(1/2):87-95

15 Tham W, Auchus AP, Thong M, et al. Progression of cognitive impairment after stroke: one year results from a longitudinal study of Singaporean stroke patients. J Neurol Sci 2002;203/204:49-52

16 Mahon S, Parmar P, Barker-Collo S, et al. Determinants, prevalence, and trajectory of long-term post-stroke cognitive impairment: results from a 4-year follow-up of the ARCOS-IV study. Neuroepidemiology 2017;49(3/4):129-134 
17 Toglia J, Fitzgerald KA, O’Dell MW, Mastrogiovanni AR, Lin CD. The Mini-Mental State Examination and Montreal Cognitive Assessment in persons with mild subacute stroke: relationship to functional outcome. Arch Phys Med Rehabil 2011;92(5):792-798

18 Dong Y, Sharma VK, Chan BP, et al. The Montreal Cognitive Assessment (MoCA) is superior to the Mini-Mental State Examination (MMSE) for the detection of vascular cognitive impairment after acute stroke. J Neurol Sci 2010;299(1/2):15-18

19 Pendlebury ST, Cuthbertson FC, Welch SJ, Mehta Z, Rothwell PM. Underestimation of cognitive impairment by Mini-Mental State Examination versus the Montreal Cognitive Assessment in patients with transient ischemic attack and stroke: a population-based study. Stroke 2010;41(6):1290-1293

20 Burton L, Tyson SF. Screening for cognitive impairment after stroke: a systematic review of psychometric properties and clinical utility. J Rehabil Med 2015;47(3):193-203
21 Lim KB, Kim J, Lee HJ, Yoo J, You EC, Kang J. Correlation between Montreal Cognitive Assessment and functional outcome in subacute stroke patients with cognitive dysfunction. Ann Rehabil Med 2018;42(1):26-34

22 Kalaria RN, Akinyemi R, Ihara M. Stroke injury, cognitive impairment and vascular dementia. Biochim Biophys Acta 2016;1862(5):915-925

23 Qu Y, Zhuo L, Li N, et al. Prevalence of post-stroke cognitive impairment in China: a community-based, cross-sectional study. PLoS One 2015;10(4):e0122864

24 Elbaz A, Vicente-Vytopilova P, Tavernier B, et al. Motor function in the elderly: evidence for the reserve hypothesis. Neurology 2013;81(5):417-426

25 Levine DA, Wadley VG, Langa KM, et al. Risk factors for poststroke cognitive decline: The REGARDS study (reasons for geographic and racial differences in stroke) Stroke 2018;49(4):987-994 